\title{
Hotéis Paulistanos: das razões da hospedagem urbana na cidade de São Paulo e as notícias em almanaques e memoriais do século XIX ${ }^{1}$
}

\author{
São Paulo Hotels: the reasons for urban housing in the city of São Paulo and the news in \\ almanacs and memorials of the nineteenth century
}

São Paulo Hoteles: las razones de la vivienda urbana en la ciudad de São Paulo y las noticias en almanaques y conmemorativo del siglo XIX

Airton José Cavenaghi ${ }^{2}$

\section{Resumo}

Este artigo, além de valorizar a produção existente relacionada a história da hotelaria na cidade de São Paulo, procura discutir a divulgação dos meios de hospedagem na cidade de São Paulo pelo uso de Almanaques e Memoriais publicados durante o século XIX. Analisa as informações divulgadas por estes veículos de informação e também estabelece diretrizes metodológicas diferenciadas para a interpretação desta documentação existente, pelo uso das técnicas historiográficas de pesquisa e análise. Pretende, desta forma, demonstrar que a história dos meios de hospedagem na cidade de São Paulo faz parte de um todo analítico vinculado a um cotidiano moldado pelas leituras possíveis do imaginário cultural do período. Procura, assim, abrir uma linha de trabalho interpretativo necessário a perceber a hotelaria paulistana pelo víeis de suas significações como instituições formadas na lógica de uma memória e de uma identidade histórica.

Palavras-chave: meios de hospedagem; história; cidade; São Paulo; século XIX.

\section{Abstract}

This article, besides valorize the existing production related to the history of hospitality in the city of São Paulo, discusses the dissemination of lodging facilities in Sao Paulo by the use of Almanacs and Memorials published during the nineteenth century. Analyzes the information disclosed by these vehicles of information and also provides different methodological guidelines for the interpretation of this existing documentation, the use of techniques historiographical research and analysis. It thereby aims to demonstrate that the history of hospitality in the city of São Paulo is part of the whole analytical linked to a possible readings everyday shaped by the cultural imagination of the period. Therefore seeking to

1 Este artigo faz parte dos resultados de pesquisa relacionados ao projeto em andamento intitulado "Requalificação do espaço e de serviços: a percepção da hospitalidade na cidade de São Paulo".

2 Doutor em História Social (FFLCH-USP), Professor Pesquisador do Mestrado em Hospitalidade da Universidade Anhembi Morumbi (UAM-SP). Email: acavenaghi@gmail.com. 
open a line of interpretive work necessary to realize the hotel in Sao Paulo by the interpretation of its meanings as institutions formed in the logic of a memory and a historical identity.

Keywords: hospitality; history; city; São Paulo; nineteen century.

\section{Resumen}

Este articulo, además de valorizar la producción existente relacionado con la historia de la hospitalidad en la ciudad de São Paulo, habla de la difusión de las facilidades de alojamiento en Sao Paulo por el uso de Almanaques y conmemorativo publicado en el siglo XIX. Analiza la información revelada por estos vehículos de información y también ofrece diferentes orientaciones metodológicas para la interpretación de esta documentación existente, el uso de técnicas de inventigación historiográfica y análisis. Con ello pretende demostrar que la historia de facilidades de alojamiento en la ciudad de São Paulo es parte del conjunto de análisis vinculados a un diario en forma de lecturas posibles de la imaginación cultural de la época. Por lo tanto tratar de abrir una línea de trabajo de interpretación necesarios para alcanzar el hotel en Sao Paulo por vieis de sus significados como las instituciones formado en la lógica de una memoria y una identidad histórica.

Palabras-chaves: hospedaje. historia. ciudad. São Paulo. siglo XIX.

\section{Introdução}

A historicidade da hotelaria em terras paulistas é desenvolvida de forma bastante elucidativa desde pelo menos 1991, quando Mário Jorge Pires publica interessante artigo no qual apontava para os "Hotéis do século XIX em São Paulo e no Rio de Janeiro: diversidade de Serviços", (PIRES, 1991); ou mais recentemente o importante trabalho de Célia Maria de Moraes Dias, "Marcos da Hospitalidade na cidade de São Paulo: amenidades e facilidades" (DIAS, 2006); ou ainda o volumoso e detalhado trabalho de Eudes Campos (2009), "Os primeiros hotéis da cidade de São Paulo Século XIX: Império e República”. Em todas as reflexões, é possível observar que a hotelaria, da maneira pensada pelo capitalismo moderno, “(...) prendeu-se ao crescimento das cidades e ao desenvolvimento dos segmentos médios da população". (PIRES, 1991, p. 55).

A cidade de São Paulo desde a época de sua fundação caracterizou por ser um local no qual o visitante encontrava grandes dificuldades em realizar sua hospedagem. Eudes Campos (2009), relembra a este respeito que: 
No princípio do século XIX, quem chegasse a São Paulo e quisesse passar alguns dias na cidade, desfrutando certo conforto e tranqüilidade, tinha de trazer na bagagem cartas de recomendação dirigidas a moradores dispostos a acolher viajantes em sua residência.

Anteriormente a este aspecto sabe-se, por exemplo, por informações das Atas da Câmara, que entre 1599 e 1603, dois estabelecimentos classificados como "hoteleiros" teriam sido criados. O primeiro gerenciado por Marcos Lopes e o segundo administrado pela cigana Francisca Rodrigues (BRUNO, 1954, p. 294). Associados a eles também se vendiam gêneros de consumo e subsistência de viajantes, que com certeza, não eram muitos.

Neste artigo pretende-se recuperar e ampliar as análises desenvolvidas por estes autores anteriormente citados, além de buscar compreender a dinâmica cotidiana da cidade de São Paulo durante o século XIX em relação os meios de hospedagem classificados e inventariados, principalmente em Almanaques e Memoriais publicados no período.

Procura, desta forma, compreender o pressuposto instituído por Jörn Rüsen, para o qual:

Histórias são verdadeiras quando seus destinatários crêem nelas. 'Crer' significa aqui [...] que as histórias exercem como que fatores de orientação, no tempo, da vida humana prática: os destinatários das histórias estão dispostos a servir-se delas para orientar-se no tempo, pois estão convictos de que histórias são capazes de tanto (RÜSEN, 2001, p. 86).

Servir-se dela, no caso a história, e de suas significações estabelecendo valores não comparativos, pois a definição dos saberes históricos; a compreensão de uma realidade pontual; encontra-se diretamente relacionada às disputas sociais, não necessariamente sangrentas, entre grupos e seus diferenciados valores (SILVA, 1995).

\section{Das Razões e Ocupações do Espaço Urbano: meios de hospedagem e identidade local,}

\section{durante o século XIX}

Os deslocamentos dos viajantes e as razões espaciais da fixação de meios de hospedagem no espaço urbano são conseqüências de um processo que envolve o conhecimento e a divulgação da cidade, e de sua lógica urbana. 
A cidade se reflete em seus elementos edificados e, neste artigo, procura-se compreender esta lógica arquitetônica e esta exposição dos valores constituídos que são expostos, por exemplo, em elementos literários, no caso os Almanaques, Indicadores e elementos iconográficos; fotografias; que refletem a constituição de uma memória coletiva no momento de sua produção.

Segundo Henrique Wanderley, para uma análise da hotelaria na percepção de seus territórios de negócios na época contemporânea, na cidade de São Paulo:

A escolha de um local para um empreendimento hoteleiro, em determinada cidade, vai depender de fatores que variam e tem pesos diferentes em relação ao tipo específico de hotel que se pretende instalar. A escolha da localização, vai depender do tipo de hotel em estudo (WANDERLEY, 2004, p. 56).

De fato o elemento de atratividade comercial é um mecanismo indutor de possibilidades de lucro. A dimensão de análise estabelecida pelo autor, representa a inserção do empreendimento em locais, cuja identidade simbólica existente referencia a aplicação dos mecanismos de gerenciamento do empreendimento, ou seja, percebe-se aquilo que já é existente e a partir desta compreensão, representada, em muitos aspectos por atributos não tangíveis, qual a possível receptividade comercial daquilo que será edificado.

Neste aspecto de análise, pode-se ainda comentar, aquilo que Luis Henrique Lemos chama de "hermenêutica do espaço", ou seja:

O espaço construído é organizado e sentido por todos aqueles que efetivamente pertencem a ele, moradores e consumidores, e está estruturado na mente desses atores na forma de localização de coisas e pessoas. (LEMOS. In: MIGUELES (org.), 2007, p. 139)

É nesta análise de Lemos (In: MIGUELES, 2007), que se torna possível observar a lógica de consumo e a formação das necessidades impostas pela presença do capitalismo em um universo histórico diferenciado da atualidade, ou seja, o modelo pensado para o passado, não é necessariamente uma reprodução dos valores e ações do presente, e é nesta forma de raciocínio que Carlos Alberto Vesentini, questiona as suas análises: "Com que critério um 
historiador fala das lutas e agentes de uma época que não é sua?” (VESENTINI, 1997, p. 15). Vesentini reproduz a lógica analítica proposta por Fernand Braudel (1970, p. 477), que nos lembra:

Civilização material: é escolher uma maneira de falar. As civilizações criam, com efeito, laços, isto é, uma ordem, entre milhares de bens culturais, de fato heteróclitos, à primeira vista como estranhos uns aos outros, desde aqueles que são do âmbito da espiritualidade e da inteligência até aos objetos e aos utensílios da vida cotidiana.

Neste aspecto, o uso de Almanaques e Memoriais, como objetos de pesquisas de documentação primárias, demonstra possibilidades infinitas para a historiografia, pois representa elementos estatísticos e demográficos, por exemplo, indicadores de uma política necessária a criar na cidade, neste caso, uma capacidade de organização e controle, relacionada diretamente a grupos sociais hegemônicos e participantes da gestão administrativa da urbe, isto pensado naquele momento específico de suas respectivas publicações.

Uma cidade que sempre foi indicada como um entroncamento de caminhos de tropas de mulas carregadas, em passagem para o porto de Santos, em um determinado momento redefine suas necessidades e passa a acomodar valores organizacionais pertinentes a esta nova realidade social e econômica que se desenhava. O tempo de análise a ser definido, representa como anteriormente definiu Vesentini, em um recorte histórico que torna possível o controle das variáveis socioculturais existentes.

Este recorte temporal, o qual não pertence o pesquisador, possui lógica organizacional e uma simbologia própria que devem ser compreendidas sem se fazer uma simples transposição de valores e ações da contemporaneidade.

A história que se analisa da presença de meios de hospedagem na cidade de São Paulo pela compreensão dos significados e exposições de propagandas existentes em seus Almanaques e Memoriais, editados no período, obedece, necessariamente, a esta perspectiva de análise histórica e cultural aqui exposta.

A presença dos estudantes da Academia de Direito a partir do ano de 1828 definiu as novas prioridades a serem atribuídas a capital da Província e este caso específico pode ser observado no tipo de publicação inicialmente impressa: tinha fins didáticos e servia para atender 
interesses específico destes novos habitantes que a cidade passava a receber, no caso como foi especificado, os estudantes da Academia.

Em termos de residências foi apenas entre 1872 e 1876 que “(...) começou a aparecer uma ou outra casa de pensão em que se hospedavam acadêmicos" (BRUNO, 1954, p. 1255).

Voltando a uma análise anterior a presença dos estudantes, ainda em 1813, por exemplo, o médico sueco Gustavo Beyer de passagem por São Paulo, argumentava: "Apesar do Brasil não ser mais considerado colônia, o estrangeiro encontra, todavia, dificuldades em viajar sem passaportes e recomendações, do que nós estavamos abundantemente munidos e dos melhores.” (BEYER, 1992, p.17).

Para o viajante não era expedido um passaporte comum, e sim uma portaria, sempre assinada pelo ministro dos negócios estrangeiros. Esta portaria garantia ao viajante uma série de benefícios, tais como transporte e hospedagem gratuita. Esta ultima sempre realizada em residência de autoridades locais ou mesmo em lugares religiosos, tais como mosteiros e conventos.

Para o viajante sem esta portaria, restava, naquele momento, locais não muito propícios a hospedagem como os ranchos dos tropeiros, existentes em grande quantidade no local no qual hoje, por exemplo, se localiza o Bairro do Bexiga, próximo ao rio Anhangabaú. Aliás, há inúmeras histórias relacionadas a isto e, talvez a mais famosa seja o relato da lendária experiência de Saint-Hilaire que em 1819, descreve com teria sido sua péssima estadia na região. (SAINT-HILAIRE, 1974). O local seria um destes entroncamentos de caminhos no qual se encontravam a estrada que vinha do interior de São Paulo, da região de Sorocaba e a que levava até Santos, no litoral, ou seja, extremamente propício ao estabelecimento deste tipo de negócio ligado a gestão das necessidades dos viajantes. No local, atualmente o Largo da Memória, na região do Vale do Anhangabaú, até hoje se ergue a Pirâmide do Piques, um marco representativo, construído pelo então engenheiro Daniel Pedro Müller em 1814, do início da Estrada projetada por ele, que levava a região de Sorocaba.

Esta realidade de uso desta portaria, que foi vivenciada por Beyer, no mesmo período, ocorreu em uma cidade de cerca de 15000 habitantes ainda concentrados em seu núcleo histórico original, na colina histórica recortada pelos rios Anhangabaú e Tamanduatei. 
A forma como Beyer descreve sua estadia demonstra que para o viajante comum as dificuldades encontradas eram ainda um problema constante e de difícil solução. Não havia um interesse em modificar-se a realidade vivenciada. A cidade ainda vivia um sono de desenvolvimento, típico das populações urbanas sem vínculos mercantis mais profundos. Vivia-se da prestação de serviços e o chamado capitalismo financeiro, era uma expressão ouvida apenas em grandes centros urbanos internacionais e, de forma ainda insipiente, na Corte, no Rio de Janeiro.

\section{A Cidade, seus Hotéis e a Representação em seus Almanaques}

Em 1857 um marco editorial acontece na cidade de São Paulo. Joaquim Roberto de Azevedo Marques, constituindo sociedade com seu irmão publicava, o "Amanak Administrativo, Mercantil e Industrial da Provincia de São Paulo”, considerado a primeira obra a elencar as características gerenciadoras da então Província de São Paulo. Aquilo que o Almanaque expõe representa um dos únicos documentos existentes a retratar o cotidiano da Província no período além de ser particularmente útil ao conhecimento daquilo que existia na capital da Província. A cidade de São Paulo contava naquele momento, por exemplo, com 05 estabelecimentos classificados como Hotéis.

Observa-se, aqui a adoção de uma significação conhecida ao editor do almanaque. Para ele fazia-se necessário a nomeação do estabelecimento, ou pela forma que ele pessoalmente já o conhecia, ou mesmo pela maneira como as pessoas no local o chamavam. Acredita-se, sem mais uma discussão aprofundada, que o espaço chamado de "hotel", poderia não possuir as características descritivas e clássicas do modelo conhecido atualmente, mas era assim que era chamado, logo, assumiu o reconhecimento coletivo pela população e assim foi representado no almanaque publicado.

O primeiro, destes hotéis, chamado de Hotel Recreio Paulistano, pertencia a Antonio Joaquim de Lima, contando com bilhar e localizando-se na Rua da Imperatriz, atual XV de Novembro. Outro chamado de Hotel Paulistano, de Adolpho Dusser, localizado na Rua de São Bento, também possuía bilhar como elemento de entretenimento aos seus hóspedes. O terceiro, chamado de Hotel Universal, pertencia a J. Lefebre, localiza-se no Largo do Colégio e também oferecia bilhar. Ainda neste contexto, poderia ser encontrado o, Café e Hotel do 
Commercio, pertencente a Hilario Pereira Magro localizado na então rua da Fundição e Largo do Colégio, junto ao Teatro. (MARQUES, 1857, p. 145).

O Café e Hotel do Commercio, não oferecia bilhar, mas anunciava que "aprompta comidas, etc.". O último estabelecimento relacionado ainda como hotel pelo Almanaque pertencia a Madame Felicia Lagarde, chamava-se Café e Hotel da Providencia e oferecia também bilhar, localizando-se na então Rua do Commercio. (MARQUES, 1857, p. 145). A antiga Rua do Commercio, atual Rua Alvares Penteado, ficava entre as atuais ruas de São Bento e Direita e sempre se mostrou um local de fluxo intenso de pessoas.

Justifica-se a presença destes estabelecimentos na região, pois em uma cidade sem ferrovias ou portos, o local de maior de fluxo de viajantes localizava-se no seu centro histórico de fundação, território de irradiação de posturas administrativas, além de ser de passagem e estadia dos eventuais viajantes.

Estes mesmos viajantes, nesta época, utilizavam-se, no caso do contato com o litoral, da chamada Estrada da Maioridade, que recebeu este nome em virtude da comemoração antecipada da maioridade do então Imperador Dom Pedro II. A estrada fora construída em substituição ao perigoso caminho da Calçada de Lorena que desde o século XVIII servia de comunicação entre o planalto e o litoral.

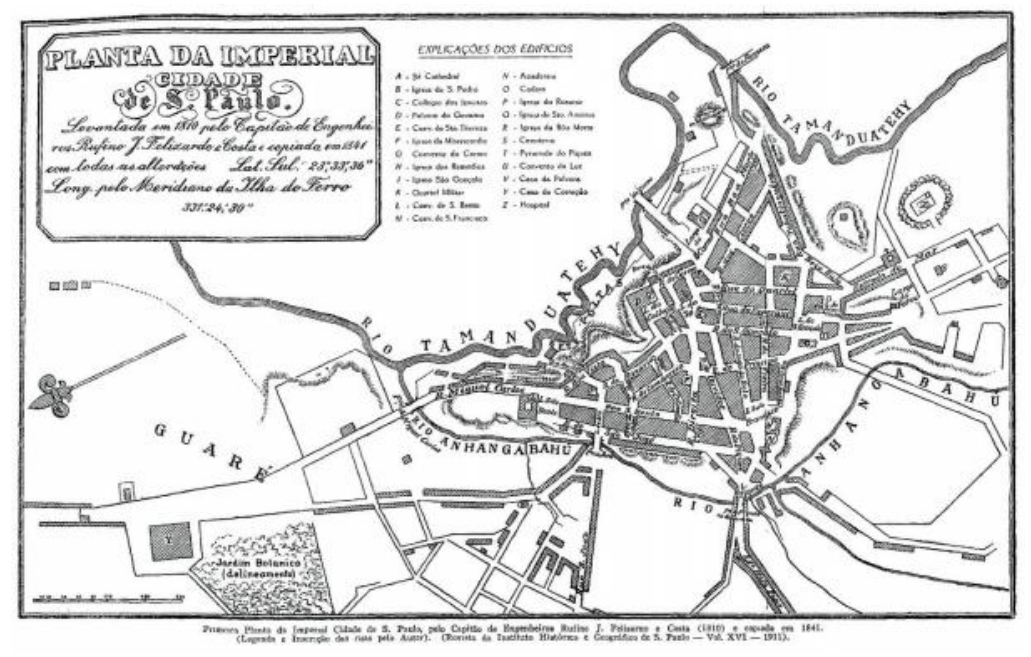

Figura 01: Planta da Imperial Cidade de São Paulo. Levantada em 1810 pelo Capitão de Engenheiros Rufino J. Felizardo e Costa e copiada em 1841 com todas as alterações.

Fonte: COMISSÃO DO IV CENTENÁRIO DE CIDADE DE SÃO PAULO (1954). 
Na disposição do mapa que mostra a cidade de São Paulo em 1841, é possível observar a questão da centralidade e do fluxo de pessoas. O mapa representa esta noção ao negligenciar, em sua representação, a periferia já existente, enfocando o centro da cidade, atribuindo, por exemplo, tons diferenciados de cinza para aquelas regiões de maior concentração populacional. Este espaço diferenciado, representado por uma cor mais escura no mapa, mostra a suposta centralidade percebida pelo cartógrafo. Nota-se, também, que havia locais já mapeados, mas ainda não ocupados, representado possibilidades de ocupação e um suposto direcionamento para futuras ações do Estado constituído. Neste espaço já mapeado, porém não ocupado, dificilmente existiria qualquer tipo de meio de hospedagem.

Neste aspecto percebe-se, a questão da ambigüidade da interpretação histórica, ou seja, a cidade que se vê no mapa é aquela que efetivamente existia, ou apenas uma representação daquela que se queria que existisse?

Uma curiosidade relacionada à presença destes meios de hospedagem localizados na região central, refere-se a necessidade de todos apresentarem, além de locais de acolhimento ao viajante, o fato de também possuírem um jogo de bilhar.

Percebe-se, assim, que este entretenimento era fundamental e visto como uma atividade necessária para a diversão naquele momento. Curiosamente a história inicial do bilhar referese à transferência do tradicional "croquet" inglês jogado ao ar livre, para o interior dos salões.

Apesar da cidade de São Paulo ainda ser influenciada pela cultura francesa no período, absorve as caracterizações culturais deste jogo neste momento, a ponto da existência de uma mesa de bilhar ser um diferencial de atração de clientes. Neste aspecto a diferenciação comercial pensada ao período, associa-se a existência de uma aparente novidade lúdica, proporcionado uma atratividade necessária ao viajante. Não são considerados, aqui, diferenciais estruturais ou de localização dos empreendimentos hoteleiros, pois todos possuíam semelhanças nestes quesitos.

No Almanaque realizado por Marques no ano seguinte, em 1858, tem-se a mesma classificação e listagem de hotéis, demonstrando poucas mudanças em relação à presença deste tipo de estabelecimento comercial na cidade de São Paulo. A novidade encontra-se no aparecimento de propagandas ilustradas, relacionadas à descrição de novos meios de hospedagem, fato que já ocorria desde 1857, segundo Eudes Campos (2009). 
Nesta época um novo empreendedor, Pedro Imbert, inaugurava o Hotel des voayageurs, no qual propagava o "bom acolhimento, e as mais agradavel hospedagem". (MARQUES, 1858, p. 412).

Pedro Imbert argumentava ainda em seu anúncio que:

Ninguem contestará, que uma das primeiras necessidades em os estabelecimentos desta ordem, é uma bem dirigida e aceiada cosinha, e neste sentido, o proprietario se ufana de haver feito a melhor acquisição a desejar, pois tem incumbido a direcção da mesma a um habil e provecto chefe, que out'ora já occupou este logar, em algumas das principais casas da aristocracia européa. (MARQUES, 1858, p. 412).

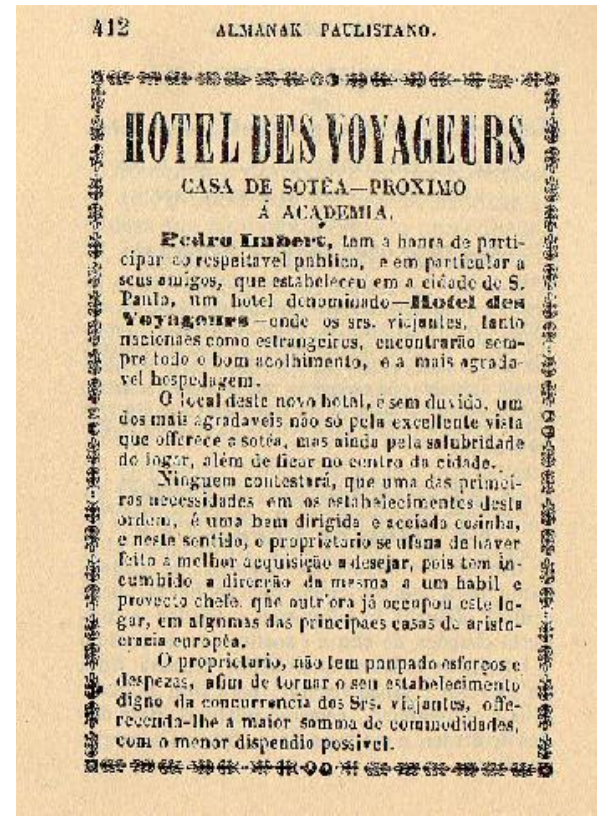

Figura 02: Detalhe Almanak Paulistano

Fonte: MARQUES, 1858, p. 412.

A propaganda do então Hotel des Voyageurs, mostra-se oportuna ao ser apontada uma nova realidade para o setor hoteleiro da cidade, ou seja, sua necessária proximidade com a questão da alimentação do hóspede. Apesar de este fato já existir, aqui fica explicitado uma preocupação com as novas realidades européias que passavam a desenhar outra faceta no desenvolvimento social e econômico da cidade de São Paulo, ou seja, sua transformação 
material e urbana seguia a tendência de acomodar a influência externa que já se apresentava bastante significativa.

Mario Jorge Pires, sobre este mesmo anúncio comenta que ele é elucidativo, pelo seu texto, pois "de fato, nos primeiros hotéis que se instalaram em São Paulo só se hospedavam forasteiros". (PIRES, 2001, p. 165). Este dado apresentado por Pires (2001) é bastante elucidativo, mas é necessário observar, também, que o autor do texto de propaganda do hotel, fez uma menção da proximidade do empreendimento a Academia de Direito, no Largo São Francisco.

Aparentemente o público consumidor do empreendimento servia as necessidades cotidianas deste mesmo local. Almeida Nogueira em suas reminiscências da Academia de Direito, relembra em várias passagens de sua obra, que os hotéis existentes na capital serviram de cenários para uma série de "aventuras" dos estudantes, além de abrigarem aqueles estudantes de maior poder aquisitivo, principalmente na segunda metade do século XIX. (NOGUEIRA, 1908, p.141 e seguintes).

Este fato é elucidado por Heloisa Barbuy que comenta que muitos dos hotéis instalados inicialmente na capital foram instalados em velhos casarões de taipa pertencentes a antiga elite administrativa ainda ligada aos momentos políticos anteriores a Independência do Brasil. Este foi o caso do Hotel de França, ou Grande Hotel de França:

[...] na esquina das ruas Direita e São Bento[...]. O casarão pertencia, em meados do século XIX, a Gertrudes Galvão d'Oliveira Lacerda Jordão[...]. Continuou [o casarão] nas mãos da família, mas poucos anos depois foi arrendado para hotel, inaugurado nos inícios da década de 1850 como Hotel das Quatro Nações. Depois se transformou em Hotel de Itália, sob gerência de José e Maria Maragliano. Na década de 1870, transformar-se-ia no Grande Hotel de França [...] (BARBUY, 2006, p.97).

O novo uso atribuído às antigas edificações urbanas foi direcionado, inicialmente, pelas necessidades deste novo grupo social, político e econômico, que passava a transformar o cotidiano da urbe desde 1828, quando a Academia de Direito passou a funcionar em São Paulo. 
Claro que somente um pequeno número destes estudantes, não seria suficiente para articular, sozinho, esta transformação radical. Este grupo acompanhou a tendência da cidade em absorver os novos valores constituídos, que seriam plenamente visualizados, apenas com o aparecimento da estrada de ferro em 1867, e principalmente mais tarde, a partir, por exemplo, da década de 80 ainda no século XIX, pelas transformações estruturais advindas com o capital cafeeiro.

Após este período inicial do Almanaque editado inicialmente por Marques, ele ainda publicaria o Memorial paulistano para o anno de 1862, de J.R.A.M., publicado, na cidade de São Paulo, em 1861 na Typographia Imparcial de J.R. de A. Marques. Essa obra saiu novamente no ano seguinte, em 1863, reaparecendo pela última vez no ano de 1866.

A crescente presença deste tipo de publicação demonstra a real necessidade de se perceber a organização administrativa da Província e, conseqüentemente, de sua capital.

\section{São Paulo na Segunda Metade do século XIX}

Esta percepção crescente da administração pública paulista em entender seu território de atuação, pode ser devidamente observada a partir do ano de 1873, quando é publicado o mais importante Almanaque do período. Tratava-se do Almanak da Província de São Paulo para 1873, organizado por Antonio José Baptista de Luné e Paulo Delfino da Fonseca. Nesta obra é possível perceber uma minuciosa coleta de informações estatísticas da Província e uma quase completa relação de estabelecimentos comerciais existentes na capital como também no resto do território paulista.

$\mathrm{Na}$ capital, objeto principal deste artigo, é possível observar a presença dos seguintes estabelecimentos classificados como "Hoteis":

No então Largo da Sé, n.02, havia o Hotel Brasil, de José Fraiss. Na então Rua do Príncipe, n. 14, é relacionado o Hotel Concordia, propriedade de Joaquim José da Silva. Na Rua Alegre, n.59, havia o Hotel da Estação, cujo proprietário não é mencionado. Na Rua da Imperatriz, n.51, de propriedade de José Planet, havia o Hotel Europa. Na Rua Direita, n. 46, era listado o Hotel Italia, de propriedade de Maria Maragliano e na Rua de São Bento, n.31, existia o Hotel Paulistano, de Rosalie Budrot. (LUNÉ, A J. B; FONSECA, P.D., 1873, p. 127). 
Nota-se, nesta relação, uma pequena mudança em relação aos locais escolhidos para o estabelecimento de meios de hospedagem na capital. Pela primeira vez aparece um estabelecimento fora do núcleo histórico original da cidade. A ferrovia que havia chegado a cidade desde 1867, passa a receber um volume cada vez maior de viajantes, mudança que, em certos aspectos, elucida o perfil da ocupação urbana da urbe. A presença do Hotel da Estação, demonstra esta transformação, apontando para o caminho de ocupação e desenvolvimento que a cidade seguia, ou seja, o ritmo dos caminhos a serem percorridos pelos viajantes.

No ano de 1872, com o crescimento do uso da ferrovia, esta necessidade organizacional proposta pelos Almanaques, chega ao interior paulista.

José Maria Lisboa, neste ano, edita o Almanak de Campinas seguido do Almanak do Rio Claro para 1873, organizado por Thomaz Carlos de Molina. Nesta obra, em especial na parte que descreve a cidade de Rio Claro, é possível perceber uma preocupação capitalista com a propagação de locais para a hospedagem de viajantes.

Neste momento, a cidade de Rio Claro possuía 04 hotéis: o Hotel d'Oeste, dirigido por Guilherme Lebeis Junior; o Hotel das Quatro Nações, dirigido por João Cezarino; o Hotel Rio-Clarence, dirigido por José Pinto da Costa Guimarães e o Hotel dos Viajantes, dirigido por Mathias Hartmann. (MOLINA, 1873, p.40). Observa-se, novamente a expressão "viajante" a nomear um meio de hospedagem. Associa-se, assim, que havia um fluxo de pessoas que estas práticas, viraram motivo de mercatilização, refletindo-se na constituição de novos setores, nas cidades em transformação estrutural.

A partir do ano de 1876, as mudanças sociais e econômicas relacionadas à cidade de São Paulo se concretizam de forma bastante acentuada, e isto pode ser percebido pela própria transformação estrutural atribuída aos Almanaques publicados em território paulista, nesta época.

Estas publicações perdem paulatinamente a característica de ser apenas um simples levantamento estatístico e passam a absorver um conteúdo mais voltado para o entretenimento e diversão. Eles se tornam menos indicativos para acomodar esta nova realidade cultural que a Província absorvia. A partir deste ano começa a ser publicada o Almanach Litterario de José Maria Lisboa, uma série de almanaques que se pautaram pela exposição de idéias e valores 
associados a elite ilustrada do período e representam os novos caminhos que a cidade passava a percorrer.

Não havia mais índices e relatórios provinciais estampados nas páginas dos almanaques. Tal fato já não era muito necessário em uma cidade que já contava com uma série de jornais diários que passaram a imprimir e divulgar, além das notícias diárias, decretos e leis administrativas, necessárias a uma nova elite de dirigentes.

Com a série de Almanaques de Lisboa é possível ver uma cidade em transformação que quer ser mais que um simples entroncamento de caminhos. Quer absorver e transmitir valores europeus, reproduzindo significados existentes nos países precursores das idéias, em especial os valores franceses já percebidos desde o ano de 1858, quando no próprio nome do estabelecimento de Pedro Imbert; Hotel des voayageurs; já se observava esta disposição.

$\mathrm{Na}$ série de almanaques de José Maria Lisboa, poucos estabelecimentos hoteleiros são relacionados. Um deles aparece já em 1877, embora o almanaque seja publicado no ano anterior, e referenciava o "Grande Hotel da Paz", de propriedade de Jules Massias, destacando o "aceio, excellente comida, preparada pelos melhores systemas culinarios(...)"; destacando ainda outra interessante particularidade, ou seja, "a linha de bonds passa na rua em que fica situado". (LISBOA, 1876, p. 80).

A presença da linha do bonde já demonstra uma cidade preocupada com a circulação e fluxo de pessoas, fato que demonstra uma transformação em relação a sua estruturação urbanística original vinculada ao contexto do chamado Triângulo Histórico: Rua de São Bento, Rua XV de Novembro e Rua Direita.

O meio de hospedagem propagava possuir "sala de banhos" e "jardim de recreio", elementos que identificam uma urbanidade crescente, além de oferecer "comida a toda hora". Oferecer alimentos aos forasteiros em todos os momentos do dia demonstra que São Paulo absorvia a tendência de centros urbanos com características metropolitanas no qual um horário fixo para as realizações cotidianas de seus habitantes, começava a perder o sentido original.

Em 1882, em viagem de retorno a São Paulo, Junius, pseudônimo de Firmo de Albuquerque Diniz, ex-estudante da academia, comentava que: 
A população parece-me tem-se aumentado em muito mais da metade; os arrabaldes estão florescentes; os costumes são outros; enfim ela apresenta o aspecto de uma cidade civilizada de movimento comercial importante, e oferecendo todos os recursos e comodidades, de que possam precisar seus habitantes e viajantes. (DINIZ, 1978, p.41).

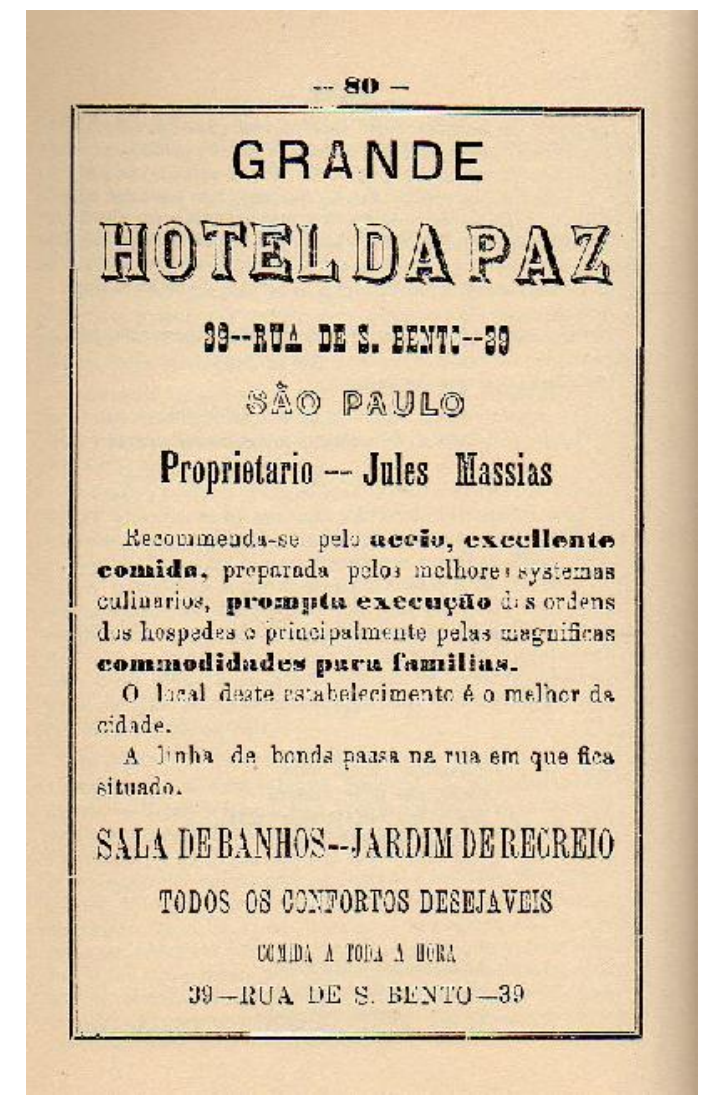

Figura 03: Detalhe Almanach Litterario Paulista para o anno de 1876

Fonte: LISBOA, 1876, p. 80.

De fato Diniz relatava o auge do momento das transformações da urbe e seu relato é quase uma obrigatoriedade de consulta documental, quando se trata de conhecer a cidade no momento destas suas modificações estruturais. Nota-se ainda que a freqüência a este tipo de estabelecimentos comerciais; hotéis, restaurantes e cafés, ainda segundo Diniz, já não era “censurado", como antes se fazia pela população local. (DINIZ, 1978, p.41). Nota-se, então que estes novos espaços já começam a configurar uma identidade própria, sendo aceitos como parte desta nova realidade citadina. O localismo da antiga praça do mercado, ou mesmo do largo da matriz, elementos fundamentais a sociabilidade da cidade na época colonial, eram 
substituídos e novos locais eram escolhidos para exercer funções semelhantes: hotéis, restaurantes e o próprio passeio público.

Os anos seguintes, para a cidade de São Paulo, seriam caracterizados por criar uma estrutura de gerenciamento e administração vinculados a uma série de elementos estruturais bem interessantes e de ampla divulgação.

Na cidade de São Paulo, já considerada um pólo irradiador de posturas, seria criado talvez a primeira obra semelhante a um guia turístico tradicional existente, no mundo na atualidade.

Em 1878, Abilio A . S. Marques, organiza o, Indicador de São Paulo, para o anno de 1878, obra que além de constar com uma série de informações indicativas da cidade, traz anexado um mapa detalhado da cidade subdividido em um mapa topográfico, a divisão das freguesias e distritos da capital e linhas de bondes, além de uma carta da comarca e município de São Paulo. (MARQUES, A.S.A, 1878, p.256).

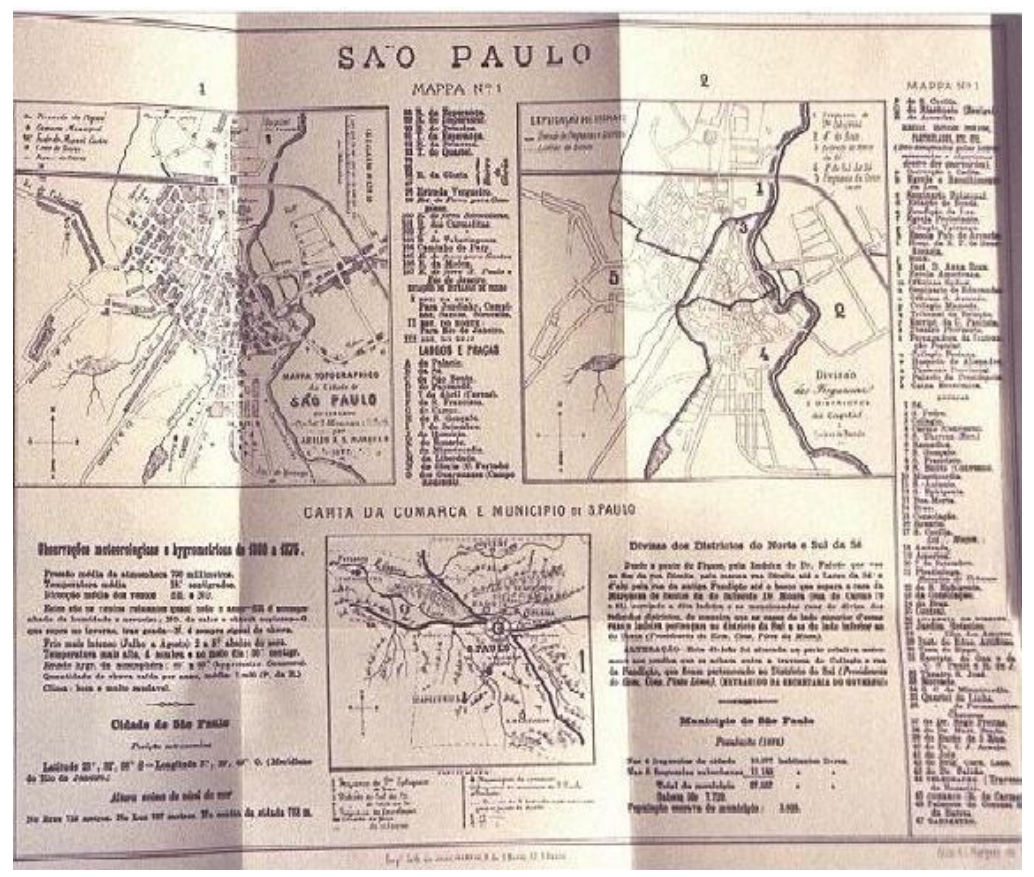

Figura 04: Detalhe Indicador de São Paulo, para o anno de 1878 Fonte: Marques, 1878, p. 256. 
A obra organizada por Abilio Marques possuía características únicas. Ela havia sido criada em função da percepção do próprio autor de que:

A população tem crescido consideravelmente; importantes melhoramentos se têm introduzido na administração; muitas e notaveis instituições publicas e particulares se têm fundado; a industria e o commercio progridem prodigiosamente; as Estradas de Ferro cruzam-se em todos os sentidos, communicando os pontos mais importantes da Provincia. (MARQUES, A.S.A, 1878, p. V).

De fato a cidade modificava-se de maneira significativa, e o fluxo de viajantes para a região tornava São Paulo um grande centro de gestão de negócios. Sua antiga característica de ser uma espécie de "entroncamento de caminhos" acomodava esta nova realidade e a quantidade de meios de hospedagem multiplicou-se de forma acentuada.

Na obra de Abilio Marques é possível observar 21 hotéis e 10 restaurantes, quantidades significativas de estabelecimentos comerciais de hospitalidade, que demonstravam como o local adaptava-se para hospedar e alimentar seus novos visitantes. (MARQUES, A. S. A., 1878, p.185-186).

No ano de 1878, José Maria Lisboa começa a dar uma nova característica aos seus Almanaques. A estrutura literária atribuída os almanaques editados a partir de então, passam a ser mais indicativa da relação de crescimento e diversidade do fluxo de visitantes existentes na cidade. O Almanach Litterario do ano de 1878 também traz encartado, assim como o Indicador de Abilio Marques, um mapa da Província de São Paulo indicando, pela primeira vez e de forma ampla, o conhecimento geográfico existente sobre o território paulista até naquele ano. Após, por exemplo, as atuais cidades de Jaboticabal e Barretos, na região Noroeste da então Província, por exemplo, a denominação do espaço territorial ficava classificada como "Terreno Desconhecido".

Como o crescimento da quantidade de meios de hospedagem na capital, a propaganda existente dos hotéis procurava valorizar elementos ligados a fluidez da cidade que começar a absorver características de uma metrópole em crescimento.

Madame Amelia Fretin, no anúncio de seu estabelecimento comentava seu hotel "o mais antigo desta capital", além de estar localizado na esquina dos "Quatro Cantos"; famoso 
cruzamento em ângulos retos das Ruas Direita e de São Bento, ponto de referência dos acontecimentos citadinos. (LISBOA, 1878, p. 142).

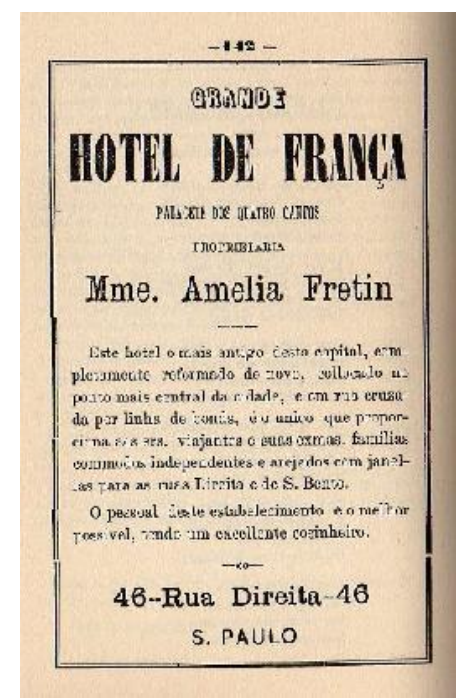

Figura 04: Detalhe Almanach Litterario Paulista para o anno de 1878

Fonte: LISBOA, 1878, p. 142.

Em relação à questão da propaganda existente para empreendimentos hoteleiros, o Almanaque passa também a estampar notícias relacionadas aos meios hospedagem, na então capital do Império, na cidade do Rio de Janeiro.

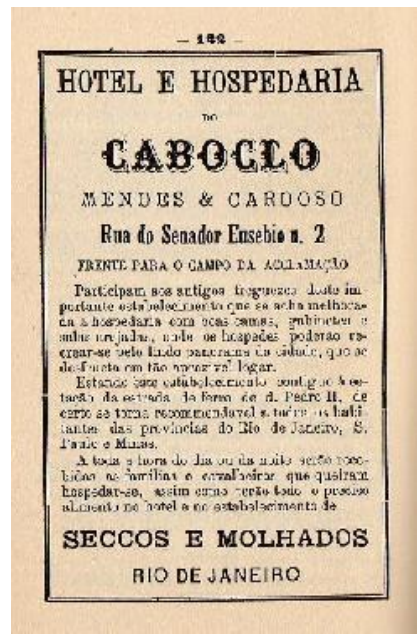

Figura 05: Detalhe Almanach Litterario Paulista para o anno de 1878 Fonte: LISBOA, 1878, p. 122. 
A presença da estrada de ferro garantia o desenvolvimento desta nova realidade, e o almanaque passa a ser considerado uma leitura de fácil compreensão típica para ser feita, por exemplo, em viagens de trens e por pessoas “(...) de poucas raízes, quem sabe novatas na terra e mal saídas das primeiras letras (...) homem típico da conquista do oeste (...) para qual a obtenção do conhecimento dava-se pela leitura rápida e, sobretudo, agradável”. (FERREIRA, 2002, p.37). Neste tipo de publicação seria o melhor espaço para a divulgação de empreendimentos associados às viagens, e neste caso passa a estampar, conforme já afirmado, propagandas de fora da Província.

Expandir-se para o interior da Província, seguindo os caminhos criados pela presença da estrada de ferro também se torna uma tendência no desenvolvimento do território paulista. Nota-se que esta preocupação já existia desde pelo menos 1872, com a publicação de Almanaques já aqui referenciados.

Neste processo de expansão do capitalismo ligado diretamente aos trilhos da estrada de ferro, no Almanaque de 1880 é encontrado o segundo anúncio relacionado a um meio de hospedagem de fora da capital e no interior da Província.

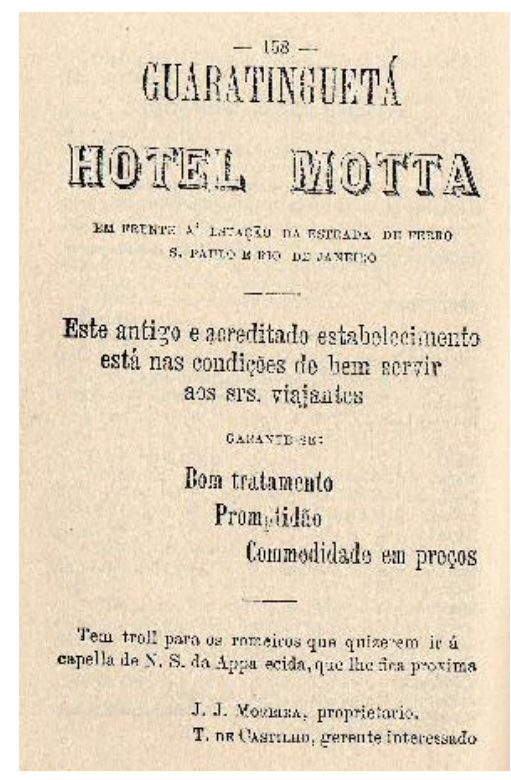

Figura 06: Detalhe Almanach Litterario Paulista para o anno de 1880 Fonte: LISBOA, 1880, p. 158. 
Nesta propaganda é estampado, talvez o primeiro anúncio de uma espécie de "tour" turístico, associado diretamente ao chamado na atualidade, Turismo Religioso: "tem troll para romeiros que quizerem ir á capella de N .S. da Apparecida, que lhe fica próxima". (LISBOA, 1880, p.158). Oferecia-se um serviço de transporte entre o Hotel em particular ao santuário de Nossa Senhora Aparecida, fato que comprova diretamente o desenvolvimento de situações nas quais é perceptível um fluxo de visitantes. Neste aspecto pode-se falar que havia no local um núcleo receptor de turismo? Da maneira que se pensa hoje o fenômeno, não; mas observase um dos elementos formativos de sua categorização atual, ou seja, percebia-se a presença de um fluxo constante de pessoas, neste caso viajantes, a ponto de se estabelecer um "serviço" de transporte ao local. (NECHAR; NETTO, 2010).

Lemos, (1987, p.30), reforçando esta análise anterior nos recorda que "o turismo nasceu em volta de bens culturais paisagísticos e arquitetônicos preservados (...)”, e desta forma aqui se encontra uma raiz significativa da forma como hoje o entendemos o turismo.

No ano de 1881 o Almanaque de Lisboa não estampou propagandas de hotéis e, por motivos desconhecidos, deixou de circular durante os dois anos seguintes. Em 1884 o Almanaque retornaria assim como as propagandas:

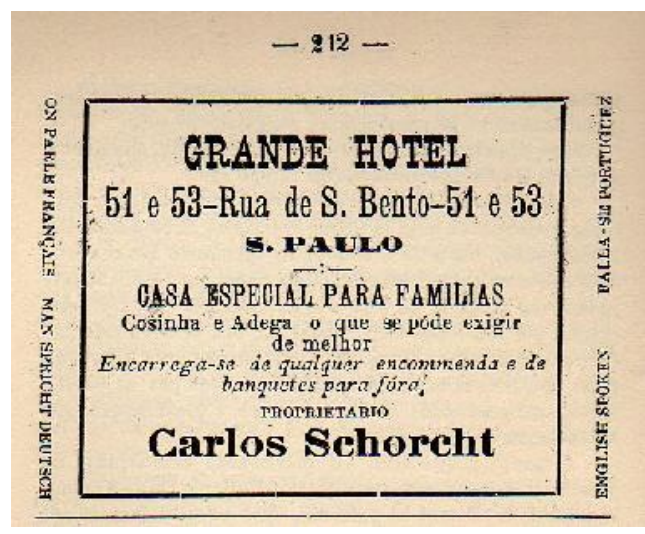

Figura 07: Detalhe Almanach Litterario Paulista para o anno de 1884

Fonte: LISBOA, 1884, p. 212. 
A propaganda realizada no Almanaque de 1884, para o Grande Hotel de Carlos Schorcht, é bastante expressiva para compreender o ritmo de desenvolvimento pelo qual São Paulo passava.

Nota-se que pela primeira vez um anúncio é vinculado para tentar captar pessoas de língua estrangeira. Argumentava-se que no hotel falava-se também em inglês, em francês e em alemão. A cidade que neste momento acomodava um enorme afluxo de imigrantes, reflete esta postura na própria forma dos empresários do setor hoteleiro passarem a pensar seus negócios e atitude administrativas que hoje nos parecem simples, na realidade, para a época na qual foram vinculadas, refletiam uma percepção aguda e futurista para os rumos dos negócios pretendidos.

Neste aspecto a documentação primária, oferecida pela análise dos Almanaques demonstra-se bastante oportuna ao refletir a realidade cotidiana que a cidade vivenciava. A presença de imigrantes era um fenômeno real que refletia nos gestos e ações das pessoas, como também na forma de se pensar os elementos organizacionais desta mesma sociedade.

Em 1885, Lisboa encerraria, agora de forma definitiva, a publicação de seus Almanaques, mas a cidade não deixaria de ter este tipo de publicação, e em seu lugar apareceria o Almanach de Jorge Seckeler.

Antigo editor de livros, estabelecido na capital desde a segunda metade do século XIX, Jorge Seckler retomaria o modelo dos Almanaques classificatórios, anteriores os de Lisboa ou seja, como muitas informações administrativas, estatísticas, classificados e com uma parte literária por vezes bem insignificante.

Seu Almanaque para o ano de 1888, trazia a seguinte listagem de Hotéis:

Agostinho Pucciarelli. Italia e Brasil, Rua de São Bento, 67; Audréa \& Poli, Internacional, Rua de São Bento, 39; Antonio de Andrade Bastos, da Estação do Braz, Rua do Braz, 141; Carlos Schorcht, Grande Hotel, Rua de São Bento, 49; Di Negro Miguel, Restaurant do Globo, Rua da Imperatriz; Francisco Gaertner, Albion, Rua do Brigadeiro Raphael Tobias, 71; Francisco Calisto Meza, d'Oeste, Largo de São Bento, 4; Guilherme Lebeis, de França, Rua Direita, 49; Hotel das Familias, Rua João Alfredo, 49; João Joaquim Flores, Rua do Braz, 143; José Frazol \& Comp., Rua da Estação, 41 e 43; Ledugerio de Souza Viana, Rua da Estação, 5; Plassas \& Irmão, Rua do Braz, 122; Severo Alouço Domingos, Hotel da Maçã de Ouro, Rua da 
Estação, 3; Viuva Rogé, Rua do Commercio, 10. (SECKLER, 1888, III parte, Secção III, p. 262).

No almanaque ainda é possível observar o crescimento de outros tipos de meios de hospedagem, com o destaque para uma hospedaria, no caso a de Adolpho Tietzmann, localizada na Rua do Bom Retiro, n. 7 (SECKLER, 1888, III parte, Secção III, p. 262,)

O hotel de Agostinho Pucciarelli, citado no Almanaque de Seckler, foi retratado por Militão Augusto de Azevedo e reflete, neste aspecto, na visão do fotógrafo, um dos melhoramentos existentes na capital no período, quando o fotógrafo realizou seu famoso Album Comparativo da cidade de São Paulo (1862-1887). Aqui se observa que o cotidiano é representativo nas ações de seus diversos personagens, ou seja, há um pensamento coletivo, neste caso as novas realidades urbanas, que se materializam naquilo que é representado.

Apesar de o endereço presente no Almanaque referenciar a Rua de São Bento n. 67, o fotógrafo Militão indicou o hotel como estando na Ladeira e Rua de São João. De fato o estabelecimento encontrava-se no cruzamento de ambas as ruas e reflete, de forma sutil pelo nome escolhido para ele, a presença de imigrantes, principalmente os italianos no novo ritmo de vida da cidade.

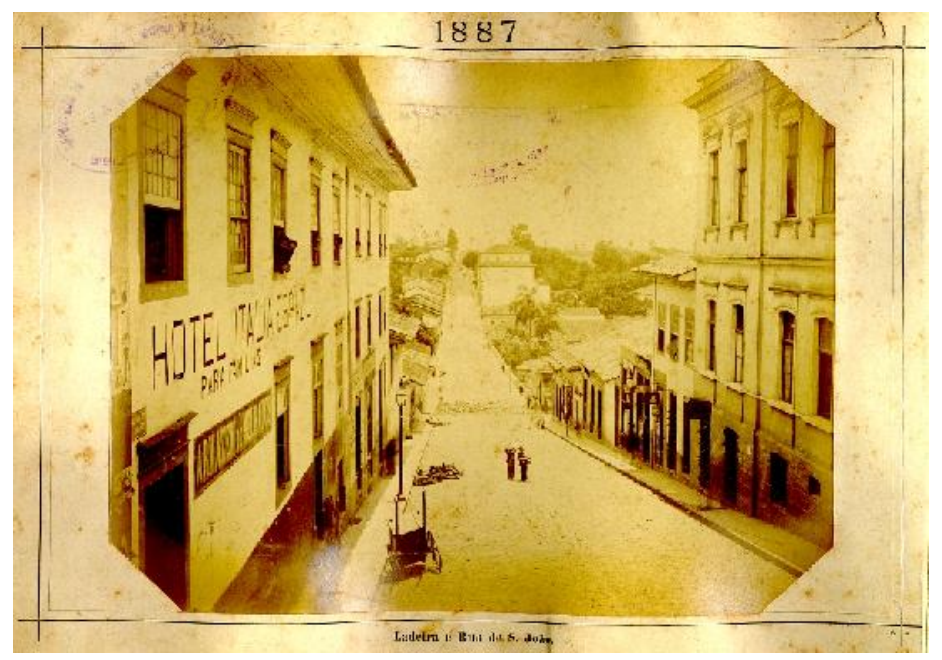

Figura 08: Fotografia Ladeira e Rua de São João

Fonte: AZEVEDO, 1887, p.06. 
A presença desta fotografia na obra organizada pelo fotógrafo Militão Augusto de Azevedo demonstra a propagação das impressões culturais relacionadas ao crescimento da urbe. As fontes diferenciadas, no caso dos Almanaques e do próprio álbum fotográfico, manifestam relações de proximidade, atestando a percepção da memória coletiva do período. (CAVENAGHI, 2000; 2008).

Novamente a análise história torna-se possível pela existência de duas fontes documentais distintas, mas que de forma inconsciente, criam um diálogo entre si.

A presença de meios de hospedagem parece ser neste momento, a resposta para uma cidade que buscava inserir-se na modernidade proposta pela presença do capitalismo em franco desenvolvimento no mundo. O real choque cultural encontra-se em observar que esta mesma sociedade ainda possuía vestígios recentes de uma política administrativa, social e econômica vinculada diretamente a um modelo escravista, apesar das transformações econômicas, refletidas na diversidade das atividades comerciais que se manifestavam pela presença da crescente economia cafeeira.

\begin{abstract}
Apesar da multiplicidade de atividades, tendo em vista a falta de especialização que caracteriza a atividade comercial no período, bilhares, botequins, cocheiras, confeitarias, hotéis, hospedarias, loja de roupas e de jóias, livrarias e teatros são identificados nas listas de pagamentos de impostos, com proprietários nitidamente de origem européia, atraídos pelas possibilidades de ocupações urbanas incrementadas com a economia cafeeira. (BASTOS, 2003, p.75).
\end{abstract}

Nos almanaques também são divulgadas, uma série de propagandas dos hotéis no interior e litoral da então Província. Sempre de locais ligados diretamente aos meios de transporte marítimo ou ferroviário.

Qual é esta cidade que acomoda estes novos desígnios necessários a estruturar uma nova realidade coletiva que se reflete em sua expansão urbana? O modelo proposto acomoda novos valores institucionais e proporciona ações satisfatórias aos seus habitantes? Estes mesmos habitantes identificam-se e reproduzem os valores necessários a manutenção de um status quo que orienta e determina as diretrizes de comportamento e de ações coletivas futuras?

O século XIX que se forma é a representação de uma modernidade aos olhos de quem os percebe nos dias atuais. No espaço real de ações dos valores que são expostos, no exato 
momento de suas reais significações, este século XIX ainda possui raízes vinculadas aos processos de seu passado formativo, que em certos aspectos, procuram sobreviver e reproduzir-se, portanto, a hotelaria paulistana no período em questão representa uma das facetas interpretativas possíveis para a análise de um todo histórico bastante significativo.

\section{Conclusões Parciais}

A análise proposta pela interpretação de um documentário histórico é restrita as observações de mundo que resultam das manifestações daqueles grupos que o criou.

O cruzamento de informações existentes em diversos suportes documentais traduz valores pertinentes de um período e induz a um acerto de analise na medida em que possibilita compreender o seu todo. A hotelaria vista pelas páginas dos Almanaques paulistanos do período é apenas um dos possíveis elementos analíticos para compreender as mudanças estruturais em desenvolvimento na cidade de São Paulo na passagem do século XIX para o século XX.

Nota-se que estas mudanças não são algo maquiavelicamente pensado são, ao contrário, fruto de situações isoladas, mas que interagem entre si de forma a criar uma situação de unidade interpretativa. O indivíduo ao observar seu cotidiano, insere, em suas ações, estas referências interpretativas recriando valores e significados que se manifestam de forma a dar-lhe certo "conforto" em sua existência, ou seja, ele identifica-se com aquilo que vê e passa a perceber que o seu espaço de ação e manutenção de valores, reproduz-se constantemente e dá significado a suas ações.

Ao apresentar-se em análises passadas apenas a perspectivas diretas da exclusiva análise do material documental existente nos Almanaques e Memoriais, relacionados ao desenvolvimento da hotelaria em terras paulistas, negligencia-se uma real situação de percepção do documento como um elemento de valor e significado mais amplo, do que as tradicionais análises que observam apenas o texto como documento.

A forma como este texto foi vinculado, o tipo de suporte utilizado em sua divulgação, a maneira na qual o autor produziu sua mensagem, entre outros fatores, representa a percepção de uma identidade mais ampla da informação historiográfica e articula novos valores que só 
poderão ser percebidos, na decomposição dos significados formativos da documentação original utilizada para análise.

Neste artigo procurou-se observar esta documentação, não apenas pela sua exposição e leitura superficial de suas mensagens. Procurou-se, acima de tudo, observar os possíveis diálogos que esta documentação pode oferecer aos olhos dos atores contemporâneos e a forma como estes mesmos atores compreendem o passado que lhes é exposto no momento da observação desta documentação primária.

\section{Referências}

ARAÚJO, Maria Lucia V. Os caminhos da riqueza dos paulistanos na primeira metade dos oitocentos. São Paulo: Hucitec, 2006.

AZEVEDO, Militão Augusto de. Álbum comparativo da cidade de São Paulo (1862-1887). São Paulo, s.d., 1887.

BARBUY, Heloisa. A Cidade-Exposição: Comércio e Cosmopolitismo em São Paulo, 1860-1914. São Paulo: EDUSP, 2006.

BASTOS, Sênia. Hospitalidade e história: a cidade de São Paulo em meados do século XIX. In: DENCKER, Ada de Freitas Maneti; BUENO, Marielys Siqueira (org.). Hospitalidade: cenários e oportunidades. São Paulo: Thomson, 2003.

BRAUDEL, Fernand. Civilização Material e Capitalismo: séculos XV-XVIII. São Paulo; Rio de Janeiro; Belo Horizonte: Edições Cosmos, 1970.

BEYER, Gustavo. Viagem a São Paulo no verão de 1813. Campinas-SP PUCCAMP, 1992.

BRUNO, Ernani da Silva. História e tradições da cidade de São Paulo. Rio de Janeiro: José Olympio, 1954.

CAMPOS, Eudes. Os primeiros hotéis da cidade de São Paulo. Século XIX: Império e República. Informativo do Arquivo Histórico Municipal. São Paulo, Ano 4, n.24, maio/junho, 2009. Disponível em: <http://www.arquiamigos.org.br/info/info24/i-estudos.htm>. Acesso em: 12/10/2010.

CAVENAGHI, Airton José. Saudosa Maloca e o patrimônio cultural imaterial constituído por Adoniran Barbosa. Anais do XX encontro regional de História. Franca: UNESP, 2010.

A cidade da fotografia - São Paulo na passagem do século XIX para o século XX. In: DEAECTO, M.M.; SECCO, L.; SILVA, M. GLEZER, R, (orgs.). São Paulo: Espaço e Memória. São Paulo : LCTE, 2008.

. Imagens que falam: olhares fotográficos sobre São Paulo (Militão Augusto de Azevedo, e "São Paulo Light and Power Co.", fins do século XIX e início do século XX). Dissertação de Mestrado. São Paulo: FFLCH/USP, 2000.

COMISSÃO DO IV CENTENÁRIO DE CIDADE DE SÃO PAULO; São Paulo antigo: plantas da cidade. São Paulo: Editora Melhoramentos, 1954.

DIAS, Célia Maria de Moraes. Marcos da hospitalidade na cidade de São Paulo: amenidades e facilidades. Revista Turismo em Análise, v.17, n.02, novembro de 2006. pp.170-189. 
DINIZ, Firmo de Albuquerque (Junius). Notas de viagem. São Paulo: Governo do Estado, 1978.

FERREIRA, Antonio Celso. A epopéia bandeirante: letrados, instituições, invenção histórica (18701940). São Paulo : UNESP, 2002.

LEMOS, Carlos A C. O que é Patrimônio Cultural. São Paulo: Brasiliense, 1987.

LISBOA, José Maria. Almanach Litterario Paulista para o anno de 1876. I anno. São Paulo: Typ. da Provincia de São Paulo, 1876; (Edição fac-similar, São Paulo : IMESP/DAESP, 1983).

LUNÉ, Antonio José Baptista de; FONSECA, Paulo Delfino da (orgs.). Almanak da Província de São Paulo. São Paulo: Typographia Americana (Largo do Palacio, n. 2), 1873. (Edição fac-similar, São Paulo: IMESP/DAESP, 1983).

MARQUES, Joaquim Roberto de Azevedo. Almanak Administrativo, Mercantil e Industrial da Província de São Paulo. São Paulo : Typographia Imparcial, 1857. (Edição fac-similar, São Paulo: IMESP/DAESP, 1983).

. Almanak Administrativo, Mercantil e Industrial da Província de São Paulo. São Paulo: Typographia Imparcial, 1858. (Edição fac-similar, São Paulo: IMESP/DAESP, 1983).

MARQUES, J. R. de A. (org.). Memorial Paulistano para o anno de 1863. Typographia Imparcial de J. R. de A. Marques, 1866 (publicado até o ano de 1866).

MARQUES, Abilio A S. (org.). Indicador de São Paulo. Administrativo, Judicial, Industrial, Profissional e Comercial. Para o anno de 1878. São Paulo: Typographia de Jorge Seckler, 1878. (Edição fac-similar, São Paulo : IMESP/DAESP, 1983).

MIGUELES, Carmen. (org.). Antropologia do consumo: caso brasileiros. Rio de Janeiro: FGV Editora, 2007.

MOLINA, Thomaz Carlos de. (org.). Almanak de São João do Rio-Claro para 1873. Campinas-SP: Typographia da Gazeta de Campinas, 1872; (Edição fac-similar, São Paulo: IMESP/DAESP, 1983).

MOURA, Denise Soares. Sociedade movediça. Economia, cultura e relações sociais em São Paulo 1808-1850. São Paulo: Unesp, 2005.

NECHAR, Marcelino Castilho; NETTO, Alexandre Panosso. Epistemologia del turismo: estúdios críticos. México: Trillas, 2010.

NOGUEIRA, Almeida. A Academia de São Paulo: tradições, reminiscências. Estudantes, estudantões e estudantadas. (quinta série). São Paulo; Lisboa: Typographia "A editora”, 1908.

OLIVEIRA, Maria Luiza Ferreira. Entre a casa e o armazém. Relações sociais e experiência da urbanização. São Paulo, Alameda, 2005.

PIRES, Mario Jorge. Raizes do Turismo no Brasil. $2^{\mathrm{a}}$ Ed. São Paulo: Manole, 2001.

Hotéis do século XIX em São Paulo e no Rio de Janeiro - Diversidade de serviços. Turismo em análise, São Paulo, v.2, n.2, p.55-64, nov. 1991.

RÜSEN, Jörn. Razão Histórica. Teoria da história: os fundamentos da ciência histórica. Brasília-DF: Editora UNB, 2001.

SAINT-HILAIRE, Auguste de. Viagem a Província de São Paulo. Belo Horizonte: Itatiaia; São Paulo: EDUSP, 1974.

SECKLER, Jorge. (org.) Almanach da Provincia de São Paulo. Administrativo, commercial e industrial. $6^{\circ}$ ano. São Paulo: Typographia a vapor de Jorge Seckler \& Comp., 1888.

SILVA, Marcos. História: o prazer em ensino e pesquisa. São Paulo: Brasiliense, 1995. 
VESENTINI, Carlos Alberto. A teia do fato. São Paulo: HUCITEC, 1997.

WARDERLEY, Henrique. A percepção dos hóspedes quanto aos atributos oferecidos pelos hotéis voltados para o turismo de negócios na cidade de São Paulo. São Paulo: Dissertação de Mestrado; POLI-USP, 2004.

Recebido em: 16/11/2010 (1 ${ }^{\text {a }}$ versão) $04 / 02 / 2011$ ( $2^{\text {a }}$ versão)

Aprovado em: 24/03/2011 